\title{
NOx sensor for exhaust applications
}

\author{
J. Lattus ${ }^{1}$, G. Hagen', J. Kita ${ }^{1}$, D. Bleicker', F. Noack ${ }^{3}$, R. Moos ${ }^{1}$ \\ ${ }^{1}$ Department of Functional Materials, Bayreuth Engine Research Center (BERC), Zentrum für \\ Energietechnik (ZET), University of Bayreuth, Universitätsstraße 30, 95440 Bayreuth, Germany \\ ${ }^{2}$ Carit Automotive GmbH \& Co KG, Gildenstr. 18, 48157 Münster, Germany \\ ${ }^{3}$ CPK Automotive GmbH \& Co. KG, Gildenstr. 4c, 48157 Münster, Germany
}

\begin{abstract}
:
Modern exhaust gas aftertreatment systems need robust and reliable sensors for in-situ control. We present a novel gas sensor that is easy to manufacture and should provide sufficient long-term stability. The impedimetric device is based on gas-depended electrical changes of a $\mathrm{NO}_{x}$ storage material, operated at higher temperatures in an equilibrium state. Experimental results demonstrate a stable baseline of the signal, high $\mathrm{NO}_{x}$ sensitivity and good $\mathrm{NO}_{x}$ selectivity regarding the missing influence of several typical exhaust gas components like $\mathrm{CO}, \mathrm{H}_{2}, \mathrm{CO}_{2}$, or $\mathrm{H}_{2} \mathrm{O}$. Notably, we found also low ammonia cross-sensitivity. Therefore, the sensor device is an interesting candidate for exhaust applications, especially in the field of selective catalytic reduction (SCR) systems.
\end{abstract}

Key words: $\mathrm{NO}_{x}$ sensor, exhaust gas aftertreatment, selective catalytic reduction (SCR), on-board diagnostics, impedance measurement, interdigital electrodes (IDE)

\section{Motivation and sensing principle}

For emission control, cheap but reliable $\mathrm{NO}_{x}$ sensor devices are needed. For this purpose, we introduce a novel impedimetric sensor.

As functional sensing component, a typical $\mathrm{NO}_{x}$ storage material similar as it is already in use for so-called $\mathrm{NO}_{x}$ storage catalyst (a.k.a. lean $\mathrm{NO}_{x}$ traps, LNT). The material itself is similar as described in [1]. Such materials form for instance nitrites and nitrates when exposed to $\mathrm{NO}_{\mathrm{x}}$. This chemical transformation leads to different materials properties. In our former investigations $\mathrm{KMnO}_{4} / \mathrm{La}-\mathrm{Al}_{2} \mathrm{O}_{3}$ utilized the likewise effect for a $\mathrm{NO}_{x}$ sensing dosimeter as described in [1]. Here, the functional material acts as a $\mathrm{NO}_{x}$ sampling device at lower temperatures resulting in an integrating sensor response (dosimeter principle).

However, in the present contribution, the sensor device is operated at higher temperatures of about $400{ }^{\circ} \mathrm{C}$ to $650{ }^{\circ} \mathrm{C}$. There is an equilibrium between ad- and desorption. Consequently, the measured signal, for example its impedance depends directly on the analyte concentration.

Since such materials are commonly used in exhaust gas catalysts, stability and robustness in exhaust gas applications should be quite high. Therefore, such sensors might be a cost efficient and serious alternative to the state of the art zirconia based devices.

\section{Sensor setup}

Sensors are built up on planar $\mathrm{Al}_{2} \mathrm{O}_{3}$ substrates. On the reverse side, a Pt heater is integrated to adjust the operating temperature. On the front side, interdigital Pt electrodes (Heraeus LPA 88, line $=$ space $=100 \mu \mathrm{m}$ ) were screen-printed as planar capacitors. The sensitive layer was also applied as a thick-film (30 to $60 \mu \mathrm{m}$ thickness) on top of the electrode area (Fig. 1). Its thicknesses could be a parameter to vary the sensitivity range.

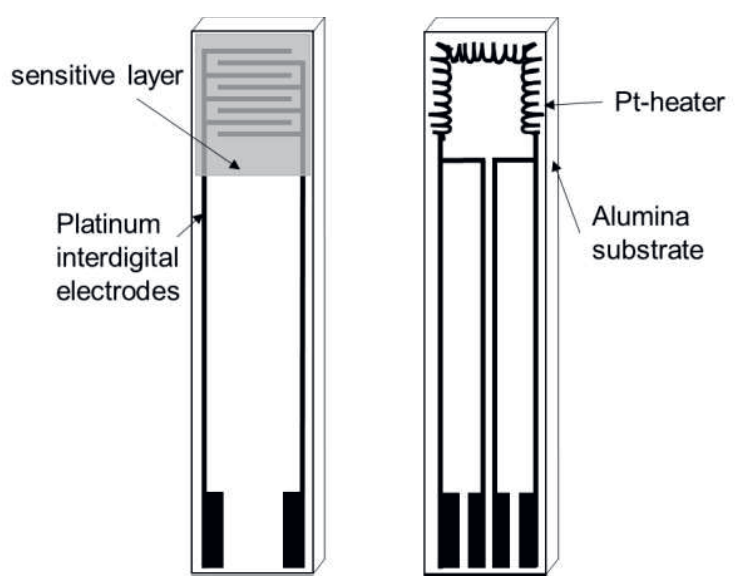

Fig. 1. Schematic layout of the front side of the sensor device with the gas sensitive layer on top of an interdigital electrode. 
In our experiments, the impedance $\underline{Z}$ and phase angle $\varphi$ are recorded by an impedance analyzer (Alpha Analyzer, Novocontrol). From both, the resistance of the sensitive layer is calculated as shown by equation (1). $R_{\text {sens }}$ is regarded as the sensor response.

$$
R_{\text {Sens }}=\frac{|\underline{Z}|}{\cos (\varphi)}
$$

\section{Experimental and results}

Test were conducted in synthetic exhaust in the lab. We exposed the sensors to an atmosphere containing $3 \% \mathrm{CO}_{2}, 5 \% \mathrm{O}_{2}$ and $3 \% \mathrm{H}_{2} \mathrm{O}$ in $\mathrm{N}_{2}$ base gas. The concentrations of the analytes were provided by several mass flow controllers. In Fig. 2, the sensor response can be seen at an operating temperature of $600{ }^{\circ} \mathrm{C}$ and a frequency of $100 \mathrm{kHz}$. The response to $\mathrm{NO}$ is reversible and there is no response to $100 \mathrm{ppm}$ $\mathrm{CO}$ and $\mathrm{H}_{2}$. In addition, the variation from $3 \%$ to $5 \% \mathrm{CO}_{2}$ or $\mathrm{H}_{2} \mathrm{O}$ respectively is not influencing the response. There is a slight cross-sensitivity to ammonia. Regarding the state-of-the art, commercial devices show much higher signal response to ammonia (up to $70 \%$ signal change for $\mathrm{NH}_{3}$ compared to the similar $\mathrm{NO}_{x}$ concentration [2].

As the sensor device can be manufactured in simple thick-film technology and can withstand the harsh environment of an automotive exhaust, an application or on-board diagnostics in light and heavy-duty vehicles as well as in building machines might be a cheap and serious alternative.

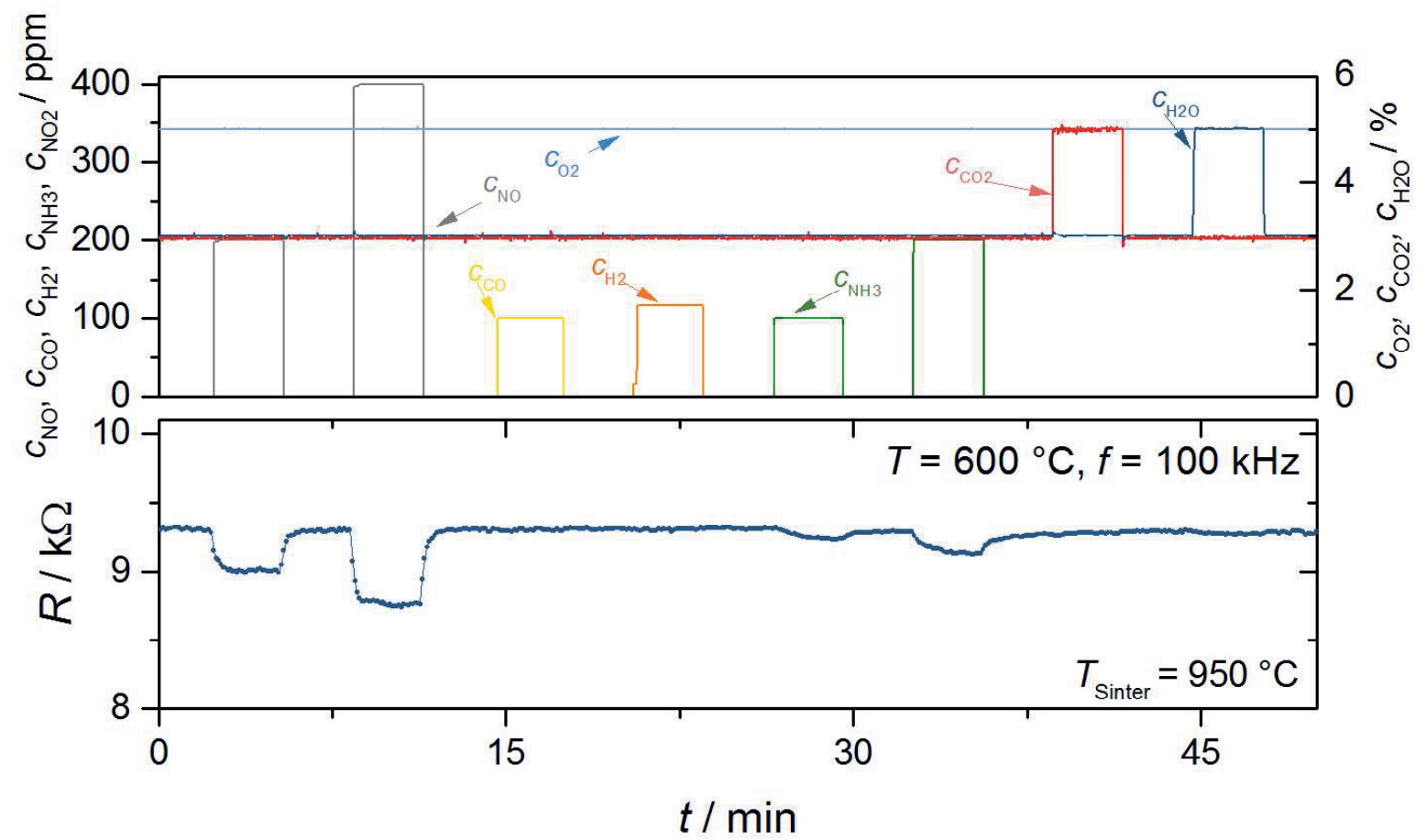

Fig.2. Sensor reaction to different gas atmospheres.

\section{References}

[1] A. Groß, M. Kremling, et al., Dosimeter-type $\mathrm{NO}_{\mathrm{x}}$ sensing properties of $\mathrm{KMnO}_{4}$ and its electrical conductivity during temperature programmed desorption, Sensors (Basel, Switzerland) 13, 4428-4449 (2013); doi: 10.3390/s130404428.

[2] A. Frobert, S. Raux, et al., About CrossSensitivities of $\mathrm{NO}_{x}$ Sensors in SCR Operation (2013); doi: 10.4271/2013-01-1512. 